\title{
Improving Frost Durability Prediction based on Relationship between Pore Structure and Water Absorption
}

\author{
Mohamed A. Aldabibi ${ }^{1}$, Michelle R. Nokken ${ }^{2}$ and Hua Ge ${ }^{3}$ \\ ${ }^{1}$ Ph.D. Candidate, Dept. of Building, Civil \& Environment Engineering, Concordia University, \\ Montreal,Canada, M_aldabibi@yahoo.com \\ ${ }^{2}$ Professor. Dept. of Building, Civil \& Environmental Engineering, Concordia University, Montreal, \\ Canada,m.nokken@concordia.ca \\ ${ }^{3}$ Associate Professor, Dept. of Building, Civil \& Environmental Engineering, Concordia University, \\ Montreal, Canada, Hua.Ge@concordia.ca
}

\begin{abstract}
In North America, clay bricks are qualified as durable if they meet either the ASTM C216 or CAN/CSA A82.1 standard. Although these standards are widely used in North America, they have not been linked with pore Structure (PS). Furthermore, moisture content and pore structure (PS) are two significant parameters that influence the performance of clay bricks during the freezing-thawing process. Thus, finding a relationship between them will lead to a quick assessment of water absorption $(W A)$ and knowing their effect on frost resistance (FR). This work aims to investigate the relationship between PS and WA of clay bricks. Five different types of clay bricks were examined. WA of brick samples was determined according to the CAN/CSA A82.1 standard. Mercury Intrusion Porosimetry (MIP) was used to determine the total porosity and pore size distribution (PSD). The variation of 24- $h$ cold water absorption (CWA) among samples of each type of brick was analyzed and each type of brick was divided into three groups according to their 24-h CWA: low-medium - high. The PSD of bricks was also divided into several ranges based on the pore size. The results indicated that some types of brick have a wide variation in 24-h CWA, which could affect the frost resistance evaluation. The strong relationship between WA and PSD was found, which could be used as a base for determining 24- $h$ CWA.
\end{abstract}

Keywords: Clay Brick, Frost Resistance, Water Absorption, Pore Structure.

\section{Introduction}

Numerous contributions in the literature have dealt with the frost durability problem regarding its mechanism and theories, influential factors, and evaluation methods (Stupart, 1989). Frost resistance (FR) is defined as the ability of materials to resist frost damage when exposed to climatic conditions (Mallidi and Reddy , 1996). Many researchers also have studied and determined the parameters that influence the FR of clay brick. They concluded that these parameters could be identified through the material characteristics and the physical state of water (ice). These studies indicated that water absorption (WA) and pore structure (PS) affect FR. Essential components of the PS of clay brick, which involve determining the FR, are its porosity and pore size distribution (PSD) (Stupart, 1989). Generally, the pores are the place where ice expansion occurs, resulting in pressure development inside porous materials.

Generated pressure typically depends upon the amount of pores and the degree of saturation of the material during the freezing process. Clay bricks typically are subjected to a wide range of water saturation levels during their service life. Hence, high levels of saturation sometimes cause durability problems, especially when it is accompanied with severe freeze/thaw $(\mathrm{F} / \mathrm{T})$ 
conditions. Water absorption is defined as the ratio between the mass of absorbed water to the dry mass of the sample (De Rose et al., 2014). The relationship between capillary pores, i.e., pores are larger than $0.01 \mu \mathrm{m}$ according to (Gao et al., 2015) and adsorbed water is a positive relation, whereas increased capillary pores lead to increased WA, which in turn affects frost durability (Davison, 1980). Thus, appropriate evaluation of potential FR of bricks requires a sufficient understanding of the relationship between FR and brick properties (i.e., PS and WA).

Predicting the FR of bricks based on a physical property assessment is known as an indirect method. In North America, the clay brick is qualified as durable if it meets the criteria based on a physical property stated in the Canadian standard CAN/CSA A82.1. The CSA A82.1 standard depends on a direct determination of compressive strength and WA. In other words, three conditions should be met which are the minimum compressive strength, maximum water absorption (i.e., 24-h CWA), and maximum saturation coefficient (C/B) (CSA-A82.1, 2006). The 24-h CWA is defined as an amount of water that absorbed during a 24-hour divided by the sample's dry mass, while $\mathrm{C} / \mathrm{B}$ is determined based on the ratio between 24-h CWA and 5-h boiling water absorption (5-h BWA). Besides, several indices have been used to evaluate potential FR such as (Maage, 1984), (Nakamura, 1988), and (Koroth et al., 1998). Maage's index (Maage, 1984) is a preferred indirect method (Davison, 1980) that is used for the evaluation ofFR. The method depends on measuring the PSD of a brick using mercury intrusion porosimetry (MIP). Ultimately, the durability factor (Df) is calculated using Eq (1) (Maage, 1984).
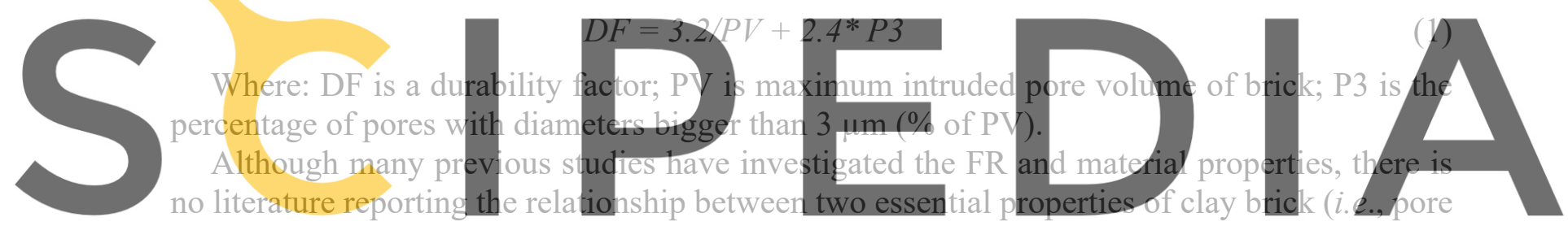

system and water absorption). The aim of this paper is to investigate the relationship between

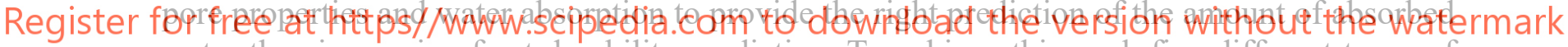
water thus improving frost durability prediction. To achieve this goal, five different types of clay brick were examined using two approaches and their measurement results were analyzed.

\section{Material and Methods}

The determination of the relationship between PS and WA properties includes several consecutive procedures. These procedures involve selecting different types of clay bricks, determining their PSD, and measuring WA. Finally, data analysis is carried out to derive the relationship between the PS and WA. To obtain a wide range of properties, five sets of brick specimens from three different types (new exterior brick, reclaimed exterior brick, and reclaimed interior brick) were obtained from local vendors in Montreal, Quebec and examined. Table 1 shows the brick types that used in this research.

\subsection{Water Absorption (WA)}

Each type of brick was tested in accordance with CSA -A82.1 standard to determine WA. First, the dried weight is determined according to CSA -A82.1 at a temperature of 110 to $115^{\circ} \mathrm{C}$ for at least $24 \mathrm{~h}$. 
Table 1. Different types of bricks used in this study.

\begin{tabular}{lccc}
\hline \multicolumn{1}{c}{ Brick Type } & Brick name & Samples number & Nomenclature \\
\hline Reclaimed exterior brick & LAPRAIRIE & 35 & PO \\
\cline { 2 - 4 } & OUTREMONT & 35 & UO \\
\hline \multirow{2}{*}{ New exterior brick } & BRGG52 & 35 & B52 \\
\cline { 2 - 4 } & OLD ENGLAND & 35 & OE \\
\hline Reclaimed interior brick & MOLLE & 35 & MO \\
\hline
\end{tabular}

\subsubsection{The 24-h cold water absorption (CWA)}

The 24-h CWA is determined according to CSA-A 82.1 following the drying and cooling procedure mentioned above. The dried full specimen was immersed completely in clean water at room temperature for $24 \mathrm{~h}$. The specimen was removed and wiped of excess water and then mass determined. The 24-h CWA is calculated based on Eq (2).

$$
\text { 24-h } C W A=\left(W_{s}-W_{d}\right) / W_{d} * 100
$$

Where: $\mathrm{W}_{\mathrm{d}}=$ dry weight of specimens; $\mathrm{W}_{\mathrm{s}}=$ saturated weight of the specimen after $24 \mathrm{~h}$ submersion in cold water.

\subsubsection{The 5-h boiling water absorption (BWA)}
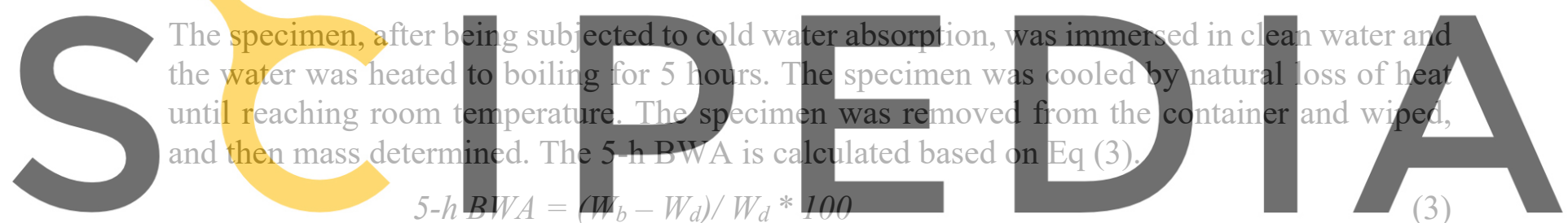

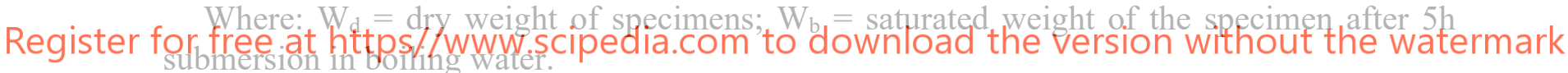

\subsection{Viercury Intrusion Porosimetry (IIIP)}

MIP has been known as a suitable method to examine the PS of mineral building materials since 1970 (Rubner and Hoffmann, 2006) and used by many researchers to determine open porosity and the PSD (Maage, 1984). A set of pore parameters can be determined and derived by MIP such as pore volume, porosity, pore range, and median pore size. The width of the PSD is expressed using the Scatter coefficient (Cd), which is calculated from Eq (4).

$$
C d=(r 20-r 80) / r 50
$$

Porosimetric determinations were performed by means of MIP (PoreSizer 9320). PSD was calculated from the mercury intrusion results by assuming a surface tension of mercury of 0.485 $\mathrm{N} / \mathrm{m}$ and a contact angle of $124^{\circ}$. The relationship between pressure and size of the pore is given by the Washburn equation (5).

$$
D=-4 \gamma \cos \theta / \rho
$$

Where: $\mathrm{D}$ is pore diameter; $\mathrm{p}=$ applied pressure; $\gamma=$ surface tension; and $\theta=$ contact angle. 
The results showed a wide range of 24-h CWA within the same brick type. To have a range of results, three samples were selected for MIP measurement from the 35 samples tested. Each type of brick was divided into three groups based on the variation in $24 \mathrm{~h}$ CWA values (low, medium, and high). Eventually, MIP test was performed on small - cored samples taken out from the brick samples to characterize the pore system. Thirty small cores, $15 \mathrm{~mm}$ in diameter and 22 to $25 \mathrm{~mm}$ length, were derived from all brick types and then examined by the MIP test with two replicates per brick type and absorption value. The small cores were dried in an oven at $105-110^{\circ} \mathrm{C}$ for $24-\mathrm{h}$ and stored in a sealed container until testing.

\section{Results and Discussion}

\subsection{Water Absorption Properties}

Thirty-five specimens of each brick type were subjected to the WA test to determine 24-h CWA, $\mathrm{C} / \mathrm{B}$, bulk density (BD), porosity (P), and apparent density (AD). Table 2 shows all brick properties that were determined based on the WA test. In general, the 24-h CWA values of the bricks as an average ranged from $4.42 \%$ (for new exterior brick OE) to about $16.68 \%$ (for reclaimed interior brick MO). Brick types $\mathrm{PO}, \mathrm{B} 52$, and $\mathrm{OE}$ on average passed the CSA - A82.1 requirement; these are all bricks intended for exterior use. However, brick types MO and UO failed to meet CSA-A82 requirements of 24-h CWA (8\%). This was somewhat surprising as UO was identified for exterior use, which is probably due to the effects of the service life. Table 2 shows the individual results of $24-\mathrm{h}$ CWA test of all brick types. Table 2 also shows that all

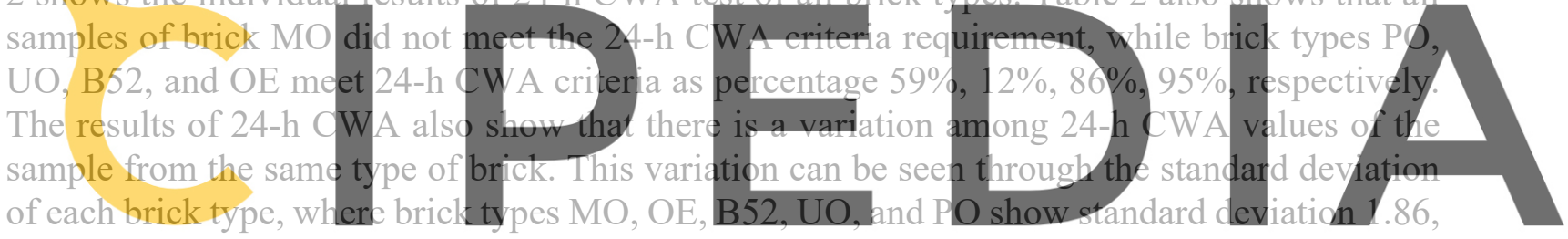
$1.80,1.65,1.38$, and 0.84 , respectively.

Register for free at https//www.scipedia.com to download the version without the watermark Table 2. Brick properties based on water absorption test.

\begin{tabular}{|c|c|c|c|c|c|c|c|c|c|}
\hline \multirow{3}{*}{$\begin{array}{l}\text { Brick } \\
\text { type }\end{array}$} & \multicolumn{4}{|c|}{ 24-h CWA \% } & \multirow{3}{*}{$\begin{array}{c}5-\mathrm{h} \\
\text { BWA } \\
\%\end{array}$} & \multirow{3}{*}{$\begin{array}{l}\text { C/B } \\
\text { Ave }\end{array}$} & \multirow{3}{*}{$\begin{array}{c}\mathrm{BD} \\
\mathrm{kg} / \mathrm{m}^{3}\end{array}$} & \multirow{3}{*}{$\begin{array}{c}\mathrm{AD} \\
\mathrm{kg} / \mathrm{m}^{3}\end{array}$} & \multirow{3}{*}{$\begin{array}{c}\mathrm{P} \\
\mathrm{m}^{3} / \mathrm{m}^{3}\end{array}$} \\
\hline & \multirow[t]{2}{*}{ Ave } & \multirow[t]{2}{*}{ SD } & \multicolumn{2}{|c|}{ Individual } & & & & & \\
\hline & & & Pass & Fail & & & & & \\
\hline $\mathrm{MO}$ & 16.68 & 1.86 & 0 & 35 & 19.62 & 0.85 & 1777 & 2725 & 0.35 \\
\hline $\mathrm{PO}$ & 7.88 & 0.84 & 20 & 15 & 10.14 & 0.78 & 2085 & 2642 & 0.21 \\
\hline UO & 9.57 & 1.38 & 5 & 30 & 12.28 & 0.78 & 1968 & 2596 & 0.24 \\
\hline B52 & 5.42 & 1.65 & 30 & 5 & 10.38 & 0.51 & 1904 & 2398 & 0.20 \\
\hline $\mathrm{OE}$ & 4.42 & 1.80 & 33 & 2 & 6.25 & 0.69 & 2245 & 2610 & 0.14 \\
\hline
\end{tabular}

The $\mathrm{C} / \mathrm{B}$ values of the bricks as an average ranged from 0.51 (for new exterior brick B52) to about 0.85 (for reclaimed interior brick MO). The results show that on average brick types B52 and OE meet the CSA-A82 requirements for exterior brick. Brick type MO also meets the CSA- 
A82 for interior brick. While brick types PO and UO exhibit the C/B at threshold 0.78 of the CSA-A82 standard as shown in Table 2 . The porosity $(\mathrm{P})$ of brick types is from $14 \%$ (for new exterior brick $\mathrm{OE}$ ) to $35 \%$ (for reclaimed interior brick MO). The bulk density (BD) of brick types is between $1777 \mathrm{~kg} / \mathrm{m}^{3}$ (for reclaimed interior brick MO) to $2245 \mathrm{~kg} / \mathrm{m}^{3}$ (for new exterior brick OE) as shown in Table 2.

\subsection{Pore System Properties}

From the MIP test, curves of cumulative pore volume and diameter were derived. Based on the calculation from Maage's equation (1) and criteria (i.e., durable DF $>70$; uncertain durability $\mathrm{DF}=55-70$; nondurable $\mathrm{DF}<55)$, most of brick types have good durability. They show (DF $>70)$ except samples MO12 - H1 and MO9- H2 that show $(\mathrm{DF}<55)$ as shown in Table 3. Brick sample OE31-H1 has the lowest pore volume (PV) compared to other samples of brick types while brick sample MO12-H1 has the highest PV. Brick sample B52-27-H2 shows a high percentage, i.e. $76 \%$, of pore volume with a diameter bigger than $3 \mu \mathrm{m}$. In contrast, brick sample MO12-H1 shows a low value, i.e. $3 \%$, of pore volume with a diameter bigger than $3 \mu \mathrm{m}$.

According to Maage's principle, sample B52-27-H2 with a DF of 226 has low water absorption and better frost resistance. In contrast, the sample MO12-H1 with a DF of 20 has high water absorption and poor frost resistance. The scattering coefficient (Cd) of all brick types ranges between 0.52 and 36. If $\mathrm{Cd}$ is less than 1, it means the PSD is narrow. The samples MO9-H2 and MO12-H1 have narrow PSD thus most ice will form within a small temperature

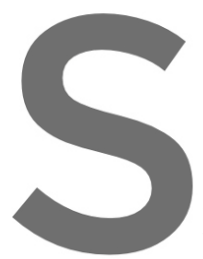
interval.

\section{The rest of the samples $\mathrm{PO}$,} a wide PSD and ice formation data analysis that saniples $\mathrm{MQ}$ predominant pore size ranges between 0.1 and pore size range between 0.3 and $1.0 \mu \mathrm{m}$. The Sample B52-27

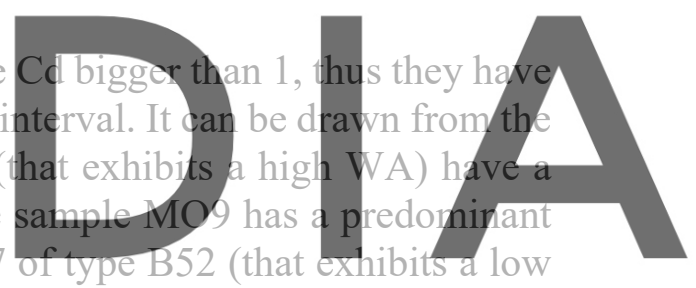
WA) has a dominant range of pore size, which is 10-20 $\mu \mathrm{m}$. Sample OE31 of type OE with the

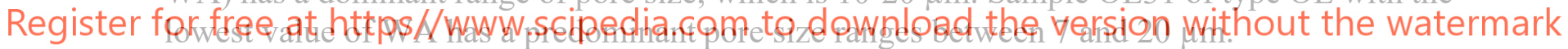

\subsection{Relationship Between 24-h CWA and PSD}

As shown in Figure 1, a linear correlation between 24-h CWA and its PV (porosity) exists with a high correlation coefficient $\left(\mathrm{R}^{2}=0.93\right)$. With the increase of porosity, i.e., pore volume, the 24-h CWA increases. To obtain a better analysis of the effect of PSD on WA, some further analysis was undertaken. Three features were investigated: PSD of the samples that had the highest and lowest values of 24-h CWA among all brick types, PSD of three samples from the same type, and PSD of the sample have the same PV. The samples MO12-H1 and MO9-H2 have the highest 24-h CWA 19.81 and 15.36, respectively. It can be seen from PSD of these samples, as shown in Figure 2, that their PSD range between 0.03 and $2 \mu \mathrm{m}$. The samples OE31$\mathrm{H} 1$ and B52-27-H2 have the lowest 24-h CWA 1.57 and 3.24, respectively with pores larger than $2 \mu \mathrm{m}$. The samples with higher porosity had smaller pores.

The PSD of three samples of brick type B52 shows that they have a bimodal pore structure (i.e., two different ranges of median and large pores). Comparing their PSD with the change in 24-h CWA, it can be observed that increasing a percentage of pores with diameters bigger than $5 \mu \mathrm{m}$ results in decreasing 24-h CWA and vice versa. The samples UO30-H2 and UO13-H1 
have approximately constant $\mathrm{PV}, 0.0906 \mathrm{ml} / \mathrm{g}$ and $0.0909 \mathrm{ml} / \mathrm{g}$, respectively. The samples PO14-H1 and OE2-H2 also have nearly the same PV, $0.1045 \mathrm{ml} / \mathrm{g}$ and $0.1039 \mathrm{ml} / \mathrm{g}$, respectively. It can be seen from Figure 3 that 24-h CWA of these samples increases with pores having diameters smaller than $2 \mu \mathrm{m}$ and vice versa. The empirical analysis of the relationship between 24-h CWA and PSD showed that 24-h CWA has a good correlation with the range of pores between 0.03 and $2 \mu \mathrm{m}$.

Table 3. Durability factor with 24-h CWA and C/B for all selected samples.

\begin{tabular}{lcccccc}
\hline \multirow{2}{*}{ Brick Sample } & \multicolumn{3}{c}{ MIP Method } & \multicolumn{3}{c}{ WA Method } \\
\cline { 2 - 7 } & PV (ml/g) & P3 (\%) & DF & Cd & 24-h CWA \% & C/B \\
\hline PO-08-H1(low) & 0.0893 & 72 & 209 & 2.74 & 6.03 & 0.74 \\
\hline PO-14-H1 (med) & 0.1045 & 58 & 170 & 2.51 & 8.04 & 0.76 \\
\hline PO-09-H2 (high) & 0.1186 & 48 & 141 & 12.38 & 9.19 & 0.77 \\
\hline UO-13-H1(low) & 0.0909 & 73 & 211 & 7.24 & 6.28 & 0.64 \\
\hline UO-30 H2(med) & 0.0906 & 46 & 146 & 8.15 & 8.94 & 0.80 \\
\hline UO-07-H1 (high) & 0.1566 & 42 & 121 & 7.49 & 11.64 & 0.79 \\
\hline MO-15-H2 (low) & 0.1485 & 25 & 82 & 36.88 & 10.62 & 0.68 \\
\hline MO-09-H2(med) & 0.1735 & 5 & 32 & 0.52 & 15.36 & 0.87 \\
\hline MO-12-H1 (high) & 0.2295 & 3 & 20 & 0.67 & 19.81 & 0.87 \\
\hline OE-31-H1 (low) & 0.0325 & 48 & 215 & 3.94 & 1.57 & 0.48 \\
\hline OE-12-H1(med) & 0.0607 & 39 & 146 & 4.32 & 5.89 & 0.76 \\
\hline
\end{tabular}
Register for free at https//www scipedia.com to download the version without the watermark

\begin{tabular}{lllllll}
\hline B52-27-H2 (low) & 0.0729 & 76 & 226 & 1.57 & 3.24 & 0.39 \\
\hline B52-31-H2(med) & 0.0681 & 73 & 213 & 1.56 & 5.87 & 0.53 \\
\hline B52-14-H2 (high) & 0.1123 & 58 & 167 & 2.41 & 8.65 & 0.64
\end{tabular}

According to findings in previous studies, which indicated that larger pores are filled with water first, then water is delivered to smaller pores (Fagerlund, 1973). Furthermore, small pores have a greater suction stress due to their diameters, but a lower rate of uptake compared with large pores. The variation between the different pore sizes will result in sucking water from the large pores and delivery to small pores. When equilibrium is reached, the movement of water will be stopped. Hence, it can be observed that water absorption is also influenced by the relationship between the amount of pores volume in the range of $0.03 \mu \mathrm{m}$ to $2 \mu \mathrm{m}$ and the amount of pores volume bigger than $2 \mu \mathrm{m}$. Thus, the parameter (A) can be derived from the empirical analysis of the relationship between these pores, as shown in Eq (6).

$$
A=(M P-L P) / L P
$$




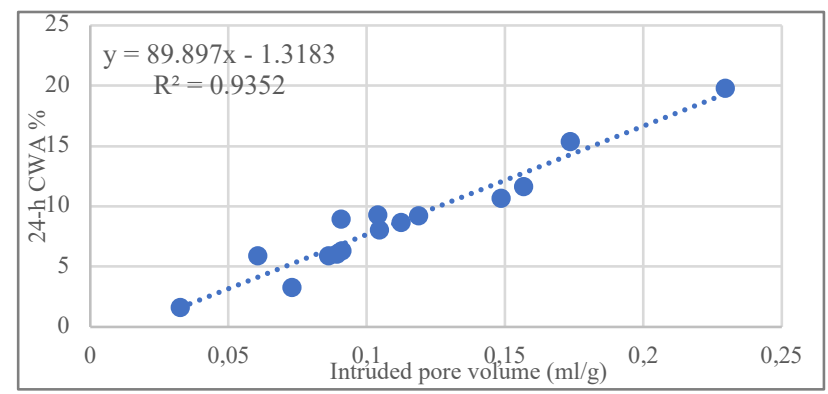

Figure 1. The correlation between 24-h CWA and intruded pore volume.

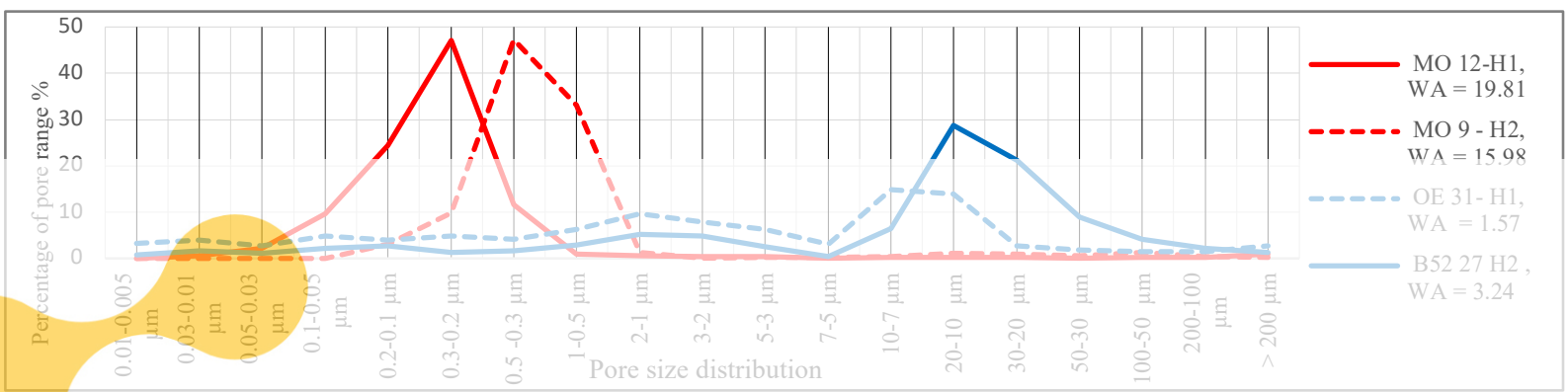

Figure 2. Pore size distribution of brick sample having maximum and minimum WA.

The ration between percentage of pores in correlation with WA. pores $(0.03-2 \mu \mathrm{m})$, perce
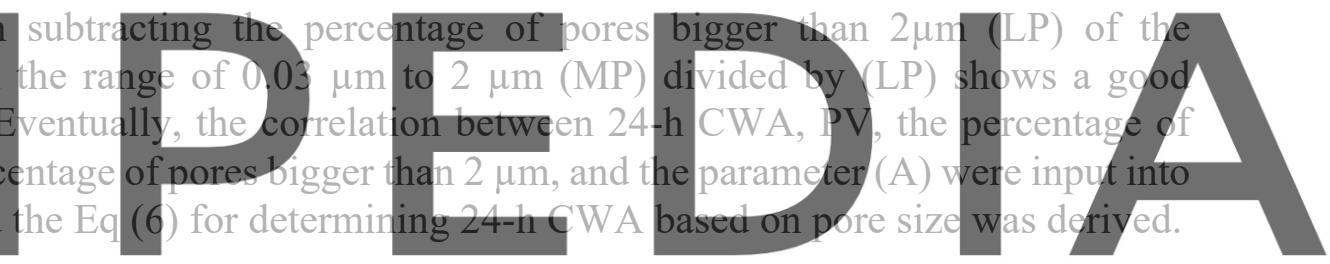

$C W A_{24-h}=59.68 P V+0.023 M P-1441.78 / L P+14.58 A+29.65 \quad\left(R^{2}=0.97\right)$

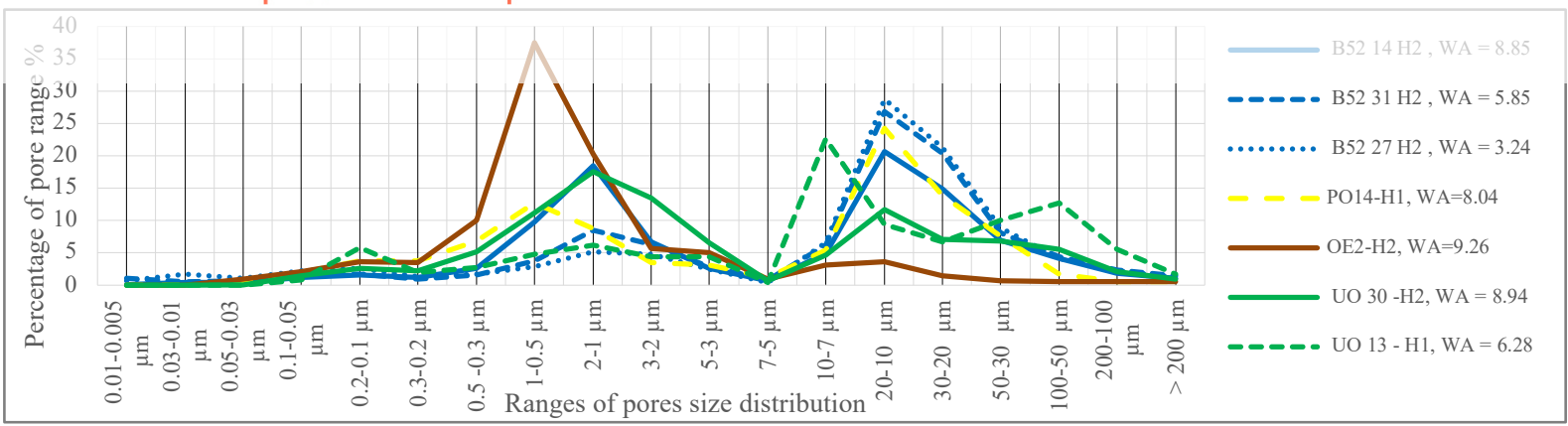

Figure 3. Pore size distribution of brick samples type B52 and other samples of different types having the same PV but with different levels of WA

\section{Conclusions}

The study investigates the relationship between WA and PS, as well as their effect on the prediction of FR. Main findings from this study are summarized as follows:

- All brick types show a variation in water absorption properties, which are essential 
elements for the evaluation of frost durability using CSA and ASTM standards. The variation may attribute to manufacturing process control and conditions exposed through their service life for reclaimed bricks. Therefore, relying on 24-h CWA and C/B for predicting frost resistance could result in a misleading assessment.

- The WA of clay brick is considerably increased with the increase of pore volume having pore size ranging between $0.03-2 \mu \mathrm{m}$. Thus, decreasing the percentage of these pores will enhance the frost resistance of clay brick.

- Despite PSD is an important factor when evaluating the FR, it is not involved in the WA method. Hence, combining PSD with WA can give a good estimation of FR.

Maage's index deals with pores bigger than $3 \mu \mathrm{m}$ as if they have uniform size and the same effect. But in fact, this contradicts several facts, namely, that pores have a different impact in terms of the size of their diameters when absorbing water. Consequently, further investigation of this issue will be required. Furthermore, a study about the relationship between the critical degree of saturation and PSD will be worthwhile to add a good contribution to the evaluation of frost resistance of clay brick.

\section{ORCID}

Mohamed A. Aldabibi: http://orcid.org/0000-0003-2146-9062

Michelle R. Nokken: http://orcid.org/0000-0002-5090-0248

Hua Ge: http://orcid.org/0000-0003-1368-4301

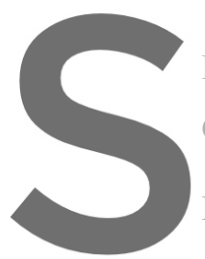

References

CSA-A 82.1. (2006). Fired

Standard Association.

Davison (1980). Liner Expansion due to Freezing and

Symposium, 13-24. Ottawa : Carleton University
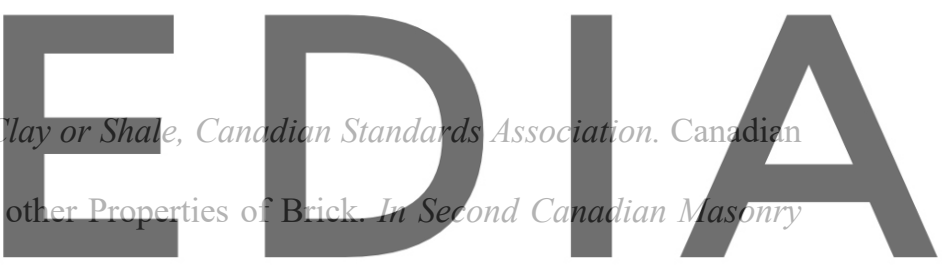

De Rose et al. (2014). Towards a limit states approach to insulating solid masonry walls in a cold climate. In 14th

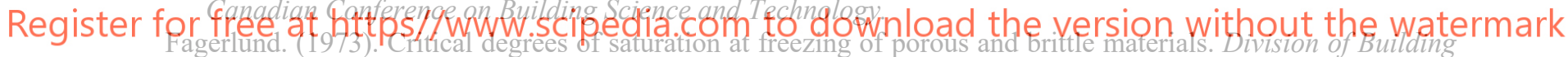
technology, Lund Institute of Technology.

Gav et al. (2015). Multi-scale simulation of capillary pores and gel pores in Portland cement paste. In 14 th International Congress on the Chemistry of Cement, 1-14.

Koroth et al . (1998). Development of new durability index for clay bricks. Journal of architectural engineering, $87-93$.

Maage. (1984). Frost Resistance and Pore Size Distribution in Brick. Material and Structure . Material Construction, 345-350.

Mallidi and Reddy . (1996). Application of mercury intrusion porosimetry on Cay Bricks to Assess Freeze - Thaw Durability - A Bibiography with Abstract. Construction and Building Materials , 461-465.

Nakamura. (1988). Indirect evaluation of frost susceptibility of building materials. American Ceramic Society bulletin, 1964-1965.

Rubner and Hoffmann. ( 2006). Characterization of mineral building materials by mercury - intrusion porosimetry. Particle systems characterization, 20-28.

Stupart. (1989). A Survey of Literature Relation to Frot Damage in Bricks. Masonry International , 42-50. 